\title{
Emotion Beliefs and Cognitive Behavioural Therapy for Social Anxiety Disorder
}

\author{
Krista De Castella ${ }^{1}$; Philippe Goldin²; Hooria Jazaieri²; \\ Richard G. Heimberg ${ }^{3}$; Carol S. Dweck ${ }^{2}$ \& James J. Gross ${ }^{2}$
}

\author{
${ }^{1}$ Australian National University \\ Research School of Psychology \\ Canberra, ACT, 0200 Australia \\ Email: Krista1@stanford.edu \\ Phone: 6506817097 \\ ${ }^{2}$ Stanford University \\ Clinically Applied Affective Neuroscience Lab (CAAN) \\ Department of Psychology \\ CA $94305-2130$ \\ Email:.pgoldin@stanford.edu; hooria@stanford.edu; \\ dweck@stanford.edu; gross@stanford.edu \\ Phone: 6507235977 \\ ${ }^{3}$ Temple University \\ Adult Anxiety Clinic of Temple (AACT) \\ Department of Psychology \\ Weiss Hall, 1701 North 13th Street \\ Philadelphia, PA 19122-6085 \\ Email: heimberg@temple.edu \\ Phone: (215) 204-7489
}

Date Submitted: August $18^{\text {th }} 2014$

\begin{abstract}
word count $=174$
Text word count $=5,194$

Tables $=3$; Figures $=2$
\end{abstract}

\section{Author Note}

We wish to thank Ihno Lee for her assistance with the statistical analyses presented in this manuscript. This research was supported by the NIMH under grant MH76074 to James Gross. Richard G. Heimberg, Ph.D., is one of the authors of the commercially available CBT protocol which was utilized in this study. The authors of this manuscript do not have any other direct or indirect conflicts of interest, financial or personal relationships or affiliations to disclose. Correspondence about this manuscript should be directed to: Krista De Castella, Research School of Psychology, Australian National University, Canberra, ACT 0200 Australia. Email: krista1@gmail.com. 


\begin{abstract}
Despite strong support for the efficacy of cognitive-behavioural therapy (CBT) for social anxiety disorder (SAD), little is known about mechanisms of change in treatment. Within the context of a randomized controlled trial of CBT, this study examined patients' beliefs about the fixed versus malleable nature of anxiety - their 'implicit theories' - as a key variable in CBT for SAD. Compared to waitlist (WL; $n=29$; 58\% female), CBT ( $n=24$; $52 \%$ female) led to significantly lower levels of fixed beliefs about anxiety ( $M_{\text {baseline }}=11.70$ vs. $\left.M_{\text {Post }}=7.08, d=1.27\right)$. These implicit beliefs indirectly explained CBT-related changes in social anxiety symptoms $\left(\kappa^{2}=.28,[95 \% \mathrm{CI}=.12, .46]\right)$. Implicit beliefs also uniquely predicted treatment outcomes when controlling for baseline social anxiety and other kinds of maladaptive beliefs (perceived social costs, perceived social self-efficacy, and maladaptive interpersonal beliefs). Finally, implicit beliefs continued to predict social anxiety symptoms at 12 months post-treatment. These findings suggest that changes in patients' beliefs about their emotions may play an important role in CBT for SAD.
\end{abstract}

Key Words: Implicit Theories; Beliefs; Social Anxiety; Emotion; CBT 


\section{Introduction}

Social anxiety disorder (SAD) is a common condition affecting approximately 15 million Americans at any one time (Kessler, Berglund, et al., 2005), with a lifetime prevalence of up to $12.1 \%$ (Kessler, Chiu, Demler, Merikangas, \& Walters, 2005). It is a chronic and disabling disorder, with symptoms typically developing at an early age and following a chronic, unremitting course (Reich, Goldenberg, Vasile, Goisman, \& Keller, 1994). SAD can interfere noticeably with daily life, often leading to avoidance behaviours, stress, and impairments in work (Bruch, Fallon, \& Heimberg, 2003), school (Kashdan \& Herbert, 2001; Schneier et al., 1994), friendships, and intimate relationships (Montesi et al., 2012; Rodebaugh, 2009).

One of the most common treatments for SAD is cognitive behavioural therapy (CBT) (Wong, Gordon, \& Heimberg, 2012). CBT for social anxiety works by altering patients’ dysfunctional beliefs through cognitive restructuring and systematic exposure to feared stimuli. Research indicates that CBT is an efficacious treatment for SAD (Ledley et al., 2009), more so than interpersonal psychotherapy (Stangier, Schramm, Heidenreich, Berger, \& Clark, 2011), psychodynamic therapy (Leichsenring et al., 2013), exposure and relaxation training (Clark et al., 2006), or treatments combining medication with either selfexposure (Clark et al., 2003) or emotional support (Mortberg, Clark, Sundin, \& Aberg Wistedt, 2007). There is also evidence that CBT results in sustained long-term improvements in SAD (Heimberg, Salzman, Holt, \& Blendell, 1993; Mortberg, Clark, \& Bejerot, 2011). However, despite clear evidence for the efficacy of CBT, many SAD patients still fail to respond to treatment (Brozovich \& Heimberg, 2011), and research is still needed on the mechanisms underlying CBT-based interventions (Hofmann, 2000).

\section{Cognitive Variables in Social Anxiety Disorder}

Cognitive models of SAD (Clark \& Wells, 1995; Heimberg, Brozovich, \& Rapee, 2010; Hofmann, 2007) outline a number of cognitive distortions and dysfunctional beliefs in 
the disorder's etiology and maintenance. In a destructive cycle, these cognitive factors are believed to lead to exaggerated emotional reactivity, dysregulation, safety and avoidance behaviour all of which further perpetuate social anxiety symptoms (Clark, 2001; Clark \& Wells, 1995). Hofmann’s (2000, 2007) model of SAD, for example, presents several maladaptive beliefs that may contribute to the disorder's maintenance. Broadly divided into three categories, these beliefs include: 1) beliefs about social situations - including unrealistic goals and expectations for social performance, poor social self-efficacy, and dysfunctional beliefs about the probability and cost of behaving poorly; 2) beliefs about the self - including negative self-perception, rumination, and heightened self-focused attention; and 3) beliefs about emotions - including the belief that one has little control over one's emotions.

Given the putative importance of cognitive variables in SAD, there is growing interest in the role they may play in treatment. For example, researchers have examined maladaptive beliefs about social situations, including beliefs about the probability of a negative social events occurring (e.g., that you will be ignored by someone you know), and the cost of these events (e.g. how bad or distressing it would be if this were to happen) (see Smits, Julian, Rosenfield, \& Powers, 2012 for a review); as well as the role of perceived social self-efficacy (e.g., the belief that you are capable of avoiding negative evaluation in social situations (Gaudiano \& Herbert, 2003; Hofmann, 2000, 2007; Leary \& Atherton, 1986). There has also been some work on the role of maladaptive self-beliefs in treatment for $\mathrm{SAD}$, for example, negative beliefs about one's appearance and performance (e.g., that one is unattractive or perceived as 'boring') (Rapee, Gaston, \& Abbott, 2009), and the role of negative interpersonal beliefs (e.g., the belief that one is 'unlovable’ or 'doesn’t fit in’) (Boden et al., 2012).

Understanding changes in cognitive processes that occur during treatment is an important goal of clinical research (Hertel \& Mathews, 2011; Hofmann, 2000). Intervening 
variables form the basis of many psychological theories and are of particular interest in clinical treatments and interventions. Despite some research on maladaptive self-beliefs and beliefs about social situations in SAD (Boden et al., 2012; Foa, Franklin, Perry, \& Herbert, 1996; Hofmann, 2004; Rapee et al., 2009), to date, there has been very little work on people's beliefs about their emotions. This is unfortunate; because there is good reason to believe emotion beliefs may have clinical significance (Hofmann, 2000, 2005, 2007; Tamir \& Mauss, 2011). The current study was designed to address this gap in the literature by examining beliefs about emotions in SAD and their potential role as a mechanism of change treatment. In the next section, we consider the literature on beliefs about emotions.

\section{Implicit Beliefs about Emotions}

Research in non-clinical samples has found that most people hold beliefs about the fixed or malleable nature of emotions (De Castella et al., 2013; Tamir, John, Srivastava, \& Gross, 2007). People holding entity beliefs about emotions more readily agree, “people can’t really change the emotions they have.” People holding incremental beliefs, on the other hand, view emotions as malleable and believe that "everyone can learn to control their emotions.” Because these beliefs are not always consciously held, they are referred to as implicit beliefs or implicit theories (see Dweck, 1999 for a review). Implicit theories, however, are traditionally measured using self-report scales and are therefore distinct from measures designed to assess implicit or automatic associations for example, as with the implicit-association-test or IAT (Greenwald, McGhee, \& Schwartz, 1998). Implicit theories also reflect broad beliefs about one's capacity for change, and in this way differ from selfefficacy beliefs, which typically assess perceived competences, and “operative capabilities as of now,” rather than potential capabilities or expected future capabilities (Bandura, 1997 p.44). In the context of social anxiety, recent work examining beliefs about emotions found that SAD patients were more likely than healthy individuals to believe that their emotions and anxiety could not be changed or controlled (De Castella et al., 2014). Entity beliefs 
about emotions also predicted more severe stress and anxiety, lower self-esteem, and poorer overall satisfaction with life. Importantly, SAD patients' beliefs about anxiety were also a stronger predictor of these outcomes than their general beliefs about emotions. In this study, we hoped to examine whether emotion beliefs also serve as an intervening variable in CBT.

\section{The Current Study}

The aim of the current study was to examine the role of emotion beliefs as a mechanism of change in CBT for social anxiety disorder. We chose to focus on beliefs about anxiety, as these beliefs may be more strongly associated with clinical outcomes than general beliefs about emotion in patients with SAD (De Castella et al., 2014). In the context of a randomized controlled trial of CBT for SAD, we hypothesized that (H1) compared to waitlist (WL) participants, patients receiving CBT would show a significant reduction in entity beliefs about anxiety. We also hypothesized that (H2) CBT would lead to reductions in social anxiety via patient's implicit beliefs about their emotions.

In addition to these two hypotheses, we wanted to examine the specificity of changes in emotion beliefs and their stability over time. We predicted that (H3) emotion beliefs would explain unique variance in post-treatment social anxiety beyond that accounted for by patients' baseline social anxiety levels or by alternative belief measures (e.g., beliefs about social costs; perceived social self-efficacy; maladaptive interpersonal beliefs). Finally, we predicted that (H4) changes in implicit beliefs during CBT would predict social anxiety at 1year follow-up.

\section{Method}

\section{Study Design}

Participants were recruited from 2007 to 2010 as part of a larger study on CBT and the neural substrates of emotion regulation in generalized SAD. The overall design of the study and its main outcomes, including adherence to CONSORT guidelines, have been reported elsewhere (Boden et al., 2012; Goldin et al., 2012). 


\section{Participants and Procedure}

Participants were 53 patients (24 men, 29 women) who completed CBT or WL in a randomized clinical control trial of CBT for social anxiety. All patients met DSM-IV (American Psychiatric Association, 1994) criteria for a primary diagnosis of generalized SAD as assessed by the Anxiety Disorders Interview Schedule for the DSM-IV-Lifetime version (ADIS-IV-L, Brown, DiNardo, \& Barlow, 1994). Patients were between 21 and 53 years of age ( $M=34 \mathrm{yrs}, S D=9.3 \mathrm{yrs})$, and were ethnically heterogeneous (62\% White; $19 \%$ Asian; 9\% Hispanic; 4\% Filipino, 2\% Pacific Islander; 4\% Other). All patients underwent extensive diagnostic screening, including telephone and in-person diagnostic interviews by clinical psychologists. Patients were ineligible if they were receiving concurrent psychotherapy or pharmacotherapy and were excluded for comorbid psychiatric disorders other than secondary diagnoses of generalized anxiety disorder, specific phobia, panic disorder, or dysthymia. After being admitted to the study, participants completed a series of online questionnaires. Patients were then randomized to 16 weekly sessions of individual CBT for SAD $(n=24)$ or a 16 -week WL group $(n=29)$. During the 16 sessions of CBT, SAD patients completed assessments of anxiety and emotion regulation (Goldin et al., 2012) as well as a battery of assessments pre- and post-treatment and at 1-year post-CBT.

\section{Measures}

\section{Implicit Beliefs about Social Anxiety}

Beliefs about the malleability of anxiety were assessed using the 4-item Implicit Beliefs About Social Anxiety Scale (De Castella et al., 2014). Based on traditional implicit theories of emotion measures (De Castella et al., 2013; Tamir et al., 2007), the IBSA contains two items assessing incremental beliefs: "If I want to, I can change the social anxiety that I have,” “I can learn to control my social anxiety,” and two items measuring entity beliefs: “The truth is, I have very little control over my social anxiety,” "No matter how hard I try, I can’t really change the social anxiety that I have.” Patients were asked to 
rate their agreement with each item on a 5-point Likert-type scale. Incremental belief items were reverse-scored and all items were summed, so that higher scores reflect greater entity beliefs and lower scores greater incremental beliefs about anxiety. Research with the IBSA indicates the scale displays high internal consistency in both non-clinical subjects (NC) and patients with SAD (NC $\alpha=.81$, SAD $\alpha=.92$ ). Moreover, the IBSA displays good convergent and discriminant validity, predicting stress and anxiety, self-esteem, and negative affect in patients with SAD (De Castella et al., 2014). All scale ranges and reliabilities at baseline and post-CBT are reported in Tables 1 and 2.

Social Anxiety

Severity of social anxiety was assessed with the self-report version of the Liebowitz Social Anxiety Scale (LSAS-SR, Fresco et al., 2001). The LSAS-SR is a commonly used, reliable, and valid measure of social anxiety (Ledley, Erwin, Morrison, \& Heimberg, 2013). The scale consists of 24 items, which independently assess fear and avoidance of social (e.g., meeting strangers) and performance (e.g., taking a written test) situations during the past week. Participants rate their fear and avoidance on a scale from 0 (no fear/avoidance) to 3 (severe fear or anxiety/ usually avoid). Total scores range from 0 to 144. Other Beliefs in SAD

To examine the specificity of emotion beliefs (H2), we included three additional measures based on existing research with SAD patients:

(1) The Social Costs Questionnaire (SCQ, Foa et al., 1996) which measures perceived costs associated with social events by asking patients to rate 40 negative hypothetical situations (e.g., "How bad would it be to unexpectedly be called in to see your supervisor at work?”). Responses are recorded on a Likert-type scale ranging from 0 (not at all bad) to 8 (extremely bad).

(2) The Perceived Social Self-Efficacy Scale (PSSE, Smith \& Betz, 2000) which assesses confidence in one's abilities to engage in social interaction tasks necessary for 
initiating and maintaining interpersonal relationships. The scale consists of 12 items (e.g., “How confident are you that you can mingle with others at a party or other social function.”) Responses are recorded on a Likert-type scale ranging from 0 (cannot do at all) to 10 (certain can do).

(3) The Maladaptive Interpersonal Beliefs Scale (MIBS, Boden et al., 2012) measures endorsement of nine negative self-beliefs relevant to SAD (e.g. "If people could see who I really am, they would reject me”). Responses are rated on a Likert-type scale ranging from 1 (Definitely false or Strongly disagree) to 5 (Definitely true or Strongly agree).

\section{Treatment}

Patients receiving CBT completed 16 individual sessions with a trained clinical psychologist. Sessions were 1hr, except for the first in-session exposure session, which lasted 1.5hrs. CBT was delivered using a manualized treatment protocol which included a therapist guide (Hope, Heimberg, \& Turk, 2006) and a client workbook (Hope, Heimberg, Juster, \& Turk, 2000) and featured training in cognitive restructuring techniques for identifying and modifying negative self-beliefs. CBT sessions also involved psychoeducation and graded exposure to anxiety-provoking situations both within session and as homework. All sessions were recorded and coded for adherence by trained researchers according to the Therapist Adherence Scale (Hope, VanDyke, Heimberg, Turk, \& Fresco, 2001). There was no significant difference between therapists on the adherence ratings $(M=$ 4.16, $S D=0.24, F(3,33)=0.11, p=.96)$.

\section{Statistical Analyses}

To evaluate the effects of CBT on patients’ implicit beliefs (H1), a 2 group (CBT vs. WL) x 2 Time (baseline vs. post-treatment/WL) repeated-measures analysis of variance (ANOVA) was conducted followed by paired-sample $t$-tests for the CBT and WL groups. Next, to test the potential intervening role of implicit beliefs (H2), while accounting for 
baseline social anxiety, we first computed orthogonalized, residual gains scores for the LSAS-SR using pre-post output residuals. Orthogonalized scores represent a measure of change during treatment that is independent of pre-treatment status. Using orthogonalized scores we were able to account for baseline social anxiety in all analyses, and control for baseline correlations between the LSAS-SR and the other belief measures. Because orthogonalized scores are uncorrelated with baseline severity, these scores also represent a more conservative estimate of change following treatment (Cohen, Cohen, West, \& Aiken, 2003). We then examined the effect of CBT vs. WL (the predictor) on the LSAS-SR residuals (the dependent variable) via patients' implicit beliefs (the intermediary). This indirect effect is quantified as the product of the coefficients, $a$ and $b$. The direct effect, $c$ ', was also estimated but is not relevant when testing mediation or indirect effects (Hayes, 2009) ${ }^{1}$ This product term (ab) was tested for significance using the Preacher and Hayes (2008; Rucker, Preacher, Tormala, \& Petty, 2011) PROCESS macro for SPSS. Unlike other traditional tests of mediation and indirect effects, such as the Sobel test (Sobel, 1982) and those presented by Baron and Kenny (1986), the bootstrap method does not assume standard errors are normally distributed, and does not compromise statistical power with multiple tests. The bootstrap method is also the preferred approach for small-to-medium samples (Tabachnick \& Fidell, 2007). We computed bias-corrected 95\% confidence intervals based on a bootstrap of 5000 samples. Gender, age and ethnicity were not associated with implicit beliefs or either of the dependent variables and were not included as covariates.

Indirect effect analyses were repeated - and measures of effect size calculated - for each of the alternative belief measures (social costs, perceived social self efficacy, and maladaptive interpersonal beliefs). To evaluate the size of the indirect effects, Preacher and

\footnotetext{
1 The Baron and Kenny (1986) causal steps approach to mediation requires that the effects of X on Y (path c), $\mathrm{X}$ on $\mathrm{M}$ (path a), and $\mathrm{M}$ on $\mathrm{Y}$ (path $\mathrm{b}$ ) are significant, as well as that the effect of $\mathrm{X}$ on $\mathrm{Y}$ controlling for $\mathrm{M}$ (path c') is smaller than c by a non-trivial amount. However, mediation effects may still be observed in the absence of a significant total effect (path c) and/or a direct effect (path c').
} 
Kelly (2011) suggest the use of Kappa Squared $\left(\kappa^{2}\right)$ - a ratio of the indirect effect to the maximum possible effect permitted by the design and data. In the current study all waitlist subjects were offered treatment at the completion of the 12-week waitlist period. For this reason, a treatment vs. waitlist-control comparison can only be made at two time points: baseline and post-treatment. We therefore examine the indirect effect of emotion beliefs and their role as a potential intervening variable rather than as a mediator of change in treatment. Results are reported as standardized coefficients.

To examine whether the patients' implicit beliefs predicted unique variance in treatment outcomes - beyond what might already be explained by their baseline social anxiety level, or by the alternative belief measures (H3) - we conducted two-step hierarchical regression analyses on the LSAS-SR residual scores. Post-treatment scores for perceived social costs (SCQ), perceived social self-efficacy (PSSE), and maladaptive interpersonal beliefs (MIBS) - were entered in the first step, followed by post-treatment implicit beliefs about social anxiety (IBSA) in the second step. Finally, to test whether CBT led to lasting changes in patients' implicit beliefs and symptoms (H4), we conducted followup assessments with subjects in the CBT group $(n=18)$ at 12-months. Changes in implicit beliefs were assessed using paired-sample $t$-tests and by examining the Pearson productmoment correlation between scores at the two time points. To examine whether implicit beliefs predicted social anxiety at follow-up, we again conducted two-step hierarchical regression analyses on 12-month LSAS-SR residual scores, which controlled for baseline social anxiety. Post-treatment scores on the alternative belief measures (SCQ, PSSE and MIBS) were entered in the first step, followed by post-treatment implicit beliefs in the second step.

\section{Results}

Prior to analysis, all variables were examined for missing values and distributional assumptions (Tabachnick \& Fidell, 2007). At baseline, there were no significant differences 
between groups in age, gender, ethnicity, income, marital status, education, current or past Axis I comorbidity, or prior experience with medication or psychotherapy. There was also no significant difference at baseline between groups on patients’ implicit beliefs about anxiety $\left(M_{C B T}=11.71, S D=3.78\right.$ vs. $\left.M_{W L}=11.97, S D=4.00\right), t(51)=-0.24, p=.81$.

\section{Implicit Beliefs and CBT for Social Anxiety}

Normality, linearity, and homogeneity of variance were all found to be satisfactory. Missing data were rare (less than 5\% on any variable) and were imputed with the overall mean for that variable - a conservative technique in such cases (Tabachnick \& Fidell, 2007). Consistent with $\mathrm{H} 1$, the repeated-measures ANOVA revealed a significant treatment $\mathrm{x}$ time interaction, $F(1,51)=30.03, p<.001, R^{2}=.37$. Follow-up planned paired $t$-tests showed that, compared to baseline, patients reported lower fixed entity beliefs about their anxiety post-CBT $\left(M_{\text {baseline }}=11.70, \mathrm{SD}=3.78, M_{\text {Post }}=7.08, S D=3.49 ; t(23)=6.18, p<.001\right)$. This was a large effect by Cohen's (1988) standards, $d=1.27$. There was, however, no significant difference over time for WL patients $\left(M_{\text {baseline }}=11.97, S D=4.00\right.$ vs. $M_{\text {Post }}=$ 12.34, $S D=3.43, d=0.10), t(28)=-0.69, p=.50$ (see Figure 1$)$.

\section{The Indirect Effect of Implicit Beliefs}

In H2, we predicted that patients’ implicit beliefs about their emotions would indirectly explain CBT-related changes in social anxiety. As predicted, the indirect effect for implicit beliefs was significant with confidence intervals excluding zero, $(a b=12.87,95 \%$ $\left.\mathrm{CI}=[5.21,24.00], \kappa^{2}=.28[95 \% \mathrm{CI}=.12, .46]\right)$. This was a large effect by Preacher and Kelly’s (2011) standards (see Figure 2). To compare the indirect effect of implicit beliefs with other intervening variables, we conducted additional analyses of indirect effects for perceived social costs (SCQ), perceived social self-efficacy beliefs (PSSE), and maladaptive interpersonal beliefs (MIBS). There were no significant indirect effects for perceived social costs (SCQ, $\left.a b=.38,95 \% \mathrm{CI}=[-3.07,4.89], \kappa^{2}=.13[95 \% \mathrm{CI}=.00, .04]\right)$ or for perceived social self-efficacy beliefs (SSE, $a b=5.04,95 \% \mathrm{CI}=[-.25,14.20], \kappa^{2}=.13[95 \% \mathrm{CI}=.01$, 
.32]). However, the indirect effect for maladaptive interpersonal beliefs (MIBS) was significant with confidence intervals excluding zero, $(a b=10.26,95 \% \mathrm{CI}=[3.85,20.29]$, $\left.\kappa^{2}=.26[95 \% \mathrm{CI}=.11, .43]\right)$. This was also a large effect by Preacher and Kelly’s (2011) standards.

\section{Implicit Beliefs and Other Belief Measures}

In H3, we predicted that implicit beliefs would explain unique variance in posttreatment social anxiety while accounting for baseline social anxiety and for the independent contribution of the other belief measures - perceived social costs (SCQ), perceived social self-efficacy (PSSE), and maladaptive interpersonal beliefs (MIBS). As predicted, implicit beliefs explained unique variance in social anxiety, above and beyond that explained by baseline social anxiety, the SCQ, PSSE, and MIBS. Table 3 displays the standardized regression coefficients $(\beta), R^{2}$, and $R^{2}$-change for this analysis.

\section{Implicit Beliefs about Anxiety at Follow-up}

In our final analysis, we examined whether CBT led to lasting changes in patients’ implicit beliefs, and if so, whether implicit beliefs would continue to predict anxiety outcomes at 12 months (H4). Of the original 24 subjects in the CBT group, 18 completed the follow-up assessment. From treatment-completion to 12-month follow-up, patients' implicit beliefs about anxiety were strongly correlated, with no significant differences between the two time points, $r=.91, p<.001,\left(M_{\text {post }}=6.44, S D=3.22 v s . M_{12 m}=6.28, S D\right.$ $=4.31 ; t(17)=0.36, p=.71)$. Results of hierarchical linear regressions revealed that posttreatment implicit beliefs and the alternative cognitive variables (SCQ, PSSE, and MIBS) together accounted for $29 \%$ of the variance in LSAS-SR residuals at 12 months $\left(R^{2}=.41, R^{2}\right.$ adjusted $=.29, F(4,19)=3.31, p<.05)$. Consistent with H4, implicit beliefs explained unique variance in social anxiety, above and beyond that explained by the alternative belief measures $\left(b=2.4, t(19)=2.06, p<.05, R^{2}\right.$ change $\left.=.13\right)$. These findings indicate that CBT- 
related changes in implicit beliefs persisted and continued to predict symptom severity 12 months after treatment completion.

\section{Discussion}

The primary aim of the current study was to examine whether patients’ implicit beliefs about their ability to control their emotions predict CBT outcomes for patients with SAD. Cognitive models of SAD (Clark \& Wells, 1995; Heimberg, Brozovich, \& Rapee, 2014; Hofmann, 2007) have emphasized the role of maladaptive beliefs and dysfunctional cognitive content - particularly dysfunctional beliefs about social situations, and dysfunctional beliefs about the self. To date, however, there has been very little emphasis on patients' beliefs about their emotions, and no studies have examined the role of emotion beliefs in CBT for SAD.

Implicit beliefs and social anxiety were assessed at baseline and at the completion of a 16-week randomized controlled trial of CBT for SAD. As predicted, patients receiving CBT (compared to waitlist controls) were less likely to hold fixed entity beliefs about their anxiety post-treatment/WL, and this shift in thinking explained treatment-related reductions in social anxiety. Additional analyses revealed that patients' implicit beliefs also uniquely predicted how much they benefited from treatment, even when controlling for baseline social anxiety and other categories of beliefs. Finally, implicit beliefs continued to predict anxiety symptoms at 12-month follow-up, uniquely explaining $13 \%$ of the variance in symptoms.

\section{Emotion Beliefs and CBT for Social Anxiety}

The current results suggest that implicit beliefs about emotions may play an important role in CBT. CBT for SAD teaches patients the skills required to confront anxiety-provoking situations and to examine the core beliefs that underlie their fears and avoidance behaviour (Heimberg et al., 2010; Hofmann, 2007). Patients learn about various cognitive distortions, attention and memory biases; are taught skills for managing and 
reducing their anxiety (Ledley et al., 2013); and are empowered to use these skills through graded exposure. In working with fear and avoidance hierarchies through treatment, patients are also provided with direct evidence that their self-reported fear and anxiety levels do change. In this way, patients in CBT may come to experience and internalize greater belief in their ability to change and control their emotions, even if this message is not explicitly emphasized as in interventions based on implicit theories of self (Blackwell, Trzesniewski, \& Dweck, 2007; Good, Aronson, \& Inzlicht, 2003).

\section{The Role of Emotion Beliefs in Treatment}

There are a number of explanations for why patients’ beliefs about their emotions may play an important role in treatment. First, Hofmann and Barlow (2002) suggest that for patients with social anxiety, it may actually be the perceived lack of control over one's emotional response - independent of judgment biases and fears of negative evaluation - that triggers fear and avoidance of social situations. This helps explain the prevalence of panic attacks among patients with SAD (Kessler et al., 2006) and why many attribute their fears more to panic attacks than traumatic events or indirect conditioning (Hofmann, Ehlers, \& Roth, 1995). In this way, if patients come to believe they have greater control over their emotions, reductions in fear and avoidance behaviour may follow.

Second, incremental beliefs about emotions may be a necessary prerequisite for many adaptive forms of emotion regulation. Tamir and Mauss (2011), for example, argue that before people initiate attempts to regulate their emotions, they must first believe that emotions can, in principle, be controlled, and they must then believe that they personally can control them. Research indicates that patients with SAD typically use maladaptive emotion regulation strategies in day-to-day life, such as situational avoidance and emotional suppression (Werner, Goldin, Ball, Heimberg, \& Gross, 2011). These strategies make sense as preventing or hiding one's emotional reactions may be perceived as the only option if patients hold fixed entity beliefs about their emotions. In non-clinical samples, entity beliefs 
about emotions have also been linked with reduced likelihood of using adaptive emotion regulation strategies like cognitive reappraisal (De Castella et al., 2013; Tamir et al., 2007). If CBT leads to a reliable shift in patients' beliefs about their emotions, this may, in turn, promote use of more adaptive emotion regulation strategies. Given that many features of psychopathology involve poorly implemented, inflexible or context-insensitive strategies (Werner \& Gross, 2009), examining how implicit beliefs influence emotion regulation choice is an important area for future research.

Third, patients' beliefs about whether they can learn to control their emotions may play a key role in their commitment to and engagement with psychotherapy. Positive expectations for change in treatment are regarded as one of the most important nonspecific factors in predicting general treatment response (Arnkoff, Glass, \& Shapiro, 2002). Positive expectations for change also predict rate of change (Price \& Anderson, 2011), and treatment outcomes (Chambless, Tran, \& Glass, 1997) for patients with SAD. Not surprisingly, these findings have led to renewed interest in motivational interviewing (MI, Miller \& Rollnick, 2002), and its manualized variant, motivational enhancement therapy (MET, Miller, Zweben, DiClemente, \& Rychtarik, 1992). Research indicates MI and MET techniques are effective additions to CBT for generalized anxiety (Westra, Arkowitz, \& Dozois, 2009), and there is some support for their efficacy with SAD patients (Buckner \& Schmidt, 2009). MI approaches, however, do not explicitly focus on patients’ beliefs about their emotions or the efficacy of treatments for managing one's anxiety. If treatment ambivalence is due in part to patients' implicit beliefs about their emotions, focusing on implicit beliefs in treatment, or as part of an orientation to treatment, may prove beneficial for improving MI and MET interventions.

Finally, before even finding their way to clinical professionals, emotion beliefs may influence patients' help-seeking behaviour and their openness to various forms of treatment. SAD is frequently misdiagnosed and under-treated, with patients often waiting more than 
nine years before finding appropriate specialist care (Wagner, Silove, Marnane, \& Rouen, 2006). If patients with SAD hold entity beliefs about their anxiety - as something that is fixed and uncontrollable rather than malleable and treatable - they may fail to seek treatment. When patients do seek help, emotion beliefs may also influence treatment preferences, with patients holding entity beliefs more readily turning to medication and symptom management over active cognitive change strategies taught in therapies like CBT. To date, there is limited work in this area, and research examining links between emotion beliefs, help-seeking, and treatment preferences is needed.

\section{Limitations and Future Directions}

Although the current study makes important contributions to research on implicit theories and social anxiety, several limitations should be noted. The first relates to measurement. As with much of the research on implicit theories (see Dweck, 1999), this study is based largely on participant self-reports. Self-report data provide valuable insights into patients' beliefs and their anxiety, and using self-reports has long been the primary approach for examining implicit theories. However, self-report methods - particularly for psychological symptoms - are not always as objective as other methods, such as independent evaluations, psychophysiological assessments, and behavioural tasks. In the future it will, therefore, be important to incorporate non-self-report measures to further replicate, and extend our findings.

A second limitation relates to the potential intervening role of cognitive variables in treatment. In the current study we examined several cognitive variables that might explain treatment outcomes in CBT for SAD. These variables included: implicit beliefs about emotion, perceived social costs, perceived social self-efficacy, and maladaptive interpersonal beliefs. By controlling for pre-treatment social anxiety, we were also able to examine the unique role of cognitive variables in treatment separate from patients' preexisting levels of anxiety. We found significant indirect effects for implicit beliefs and 
maladaptive interpersonal beliefs. Indirect effects however, are not evidence of causation, and they do not rule out the possibility of other additional intervening variables. Researchers for example, have also examined the potential mediating role of emotion regulation strategies (Goldin et al., 2012), negative self-talk (Kendall \& Treadwell, 2007), as well as attention, memory and information processing biases relevant to fear and anxiety (Hofmann, Moscovitch, Kim, \& Taylor, 2004; Mansell \& Clark, 1999). It will therefore be important in future research to directly examine the relative strength of these and other candidate variables, and their role in treatment. By incorporating experimental manipulations; clinical interventions; and/or multiple assessments throughout treatment, future studies may also be able to better clarify whether cognitive variables play a causal role in treatment.

A final limitation relates to generalizability. Patients in the current study were carefully screened and motivated to undertake treatment. They also completed multiple interviews and assessments that were part of the research programme. Given that many patients fail to even seek treatment (especially patients with SAD), it is entirely likely that entity beliefs about emotions are even more prevalent among non-treatment-seekers in the general population. Furthermore, from the current study should also only be generalized to CBT for SAD. It remains to be seen whether implicit beliefs about emotions explain treatment-related gains in other disorders, and in other forms of psychotherapy, or whether findings reported in the current study are unique to CBT for SAD alone.

In sum, this randomized controlled trial provides evidence for the role of implicit beliefs in cognitive-behavioral therapy for SAD. While there has been growing research on the role of cognitive variables in treatment for $\mathrm{SAD}$, to date, there is limited research on patients' beliefs about their emotions. We found that CBT led to a reliable long-term change in patients' implicit beliefs. Implicit beliefs, in turn, explained treatment related reductions in social anxiety and accounted for unique variance in symptoms over and above that explained by baseline anxiety and alternative cognitive variables - perceived social costs, 
perceived social self-efficacy, and maladaptive interpersonal beliefs. These findings indicate that maladaptive beliefs - particularly about the self and about one’s emotions - may be important mediating variables in CBT for SAD. Implicit beliefs about emotions appear to be a fruitful area for future research and may come to play an important role in conceptualizations of the etiology and treatment of social anxiety. 
Table 1. Descriptive Statistics and Correlations of Study Variables at Baseline ( $n=53)$.

\begin{tabular}{|c|c|c|c|c|c|c|c|c|c|}
\hline \multirow[b]{2}{*}{ Variable } & \multirow[b]{2}{*}{$M$} & \multirow[b]{2}{*}{$S D$} & \multirow{2}{*}{$\begin{array}{c}\text { Possible } \\
\text { Range }\end{array}$} & \multirow[b]{2}{*}{$\alpha$} & \multicolumn{5}{|c|}{ Correlations } \\
\hline & & & & & 1 & 2 & 3 & 4 & 5 \\
\hline 1. Entity Beliefs about Anxiety (IBSA) & 11.85 & 3.87 & $4-20$ & .78 & 1 & $.28^{*}$ & .23 & -.17 & $.39^{* *}$ \\
\hline 2. Social Anxiety (LSAS-SR) & 82.76 & 19.36 & $0-144$ & .92 & & 1 & $.28^{*}$ & $-.48^{* * *}$ & $.46^{* * *}$ \\
\hline 3. Social Costs (SCQ) & 205.4 & 47.08 & $0-320$ & .96 & & & 1 & $-.35^{* *}$ & $.35^{* *}$ \\
\hline 4. Perceived Social Self-Efficacy (PSSE) & 50.85 & 20.33 & $0-120$ & .90 & & & & 1 & $-.52^{* * *}$ \\
\hline 5. Interpersonal Beliefs (MIBS) & 30.36 & 5.54 & $9-45$ & .85 & & & & & 1 \\
\hline
\end{tabular}

Note: IBSA = Implicit Beliefs about Social Anxiety Scale; LSAS-SR = Liebowitz Social Anxiety Scale-Self Report. ${ }^{*} p<.05,{ }^{* *} p<.01,{ }^{* * *} p<.001$ 
Table 2. Descriptive Statistics and Correlations of Variables Post-Treatment for CBT patients $(n=24)$.

\begin{tabular}{|c|c|c|c|c|c|c|c|c|c|}
\hline \multirow[b]{2}{*}{ Variable } & \multirow[b]{2}{*}{$M$} & \multirow[b]{2}{*}{$S D$} & \multirow[b]{2}{*}{$\begin{array}{c}\text { Possible } \\
\text { Range }\end{array}$} & \multirow[b]{2}{*}{$\alpha$} & \multicolumn{5}{|c|}{ Correlations } \\
\hline & & & & & 1 & 2 & 3 & 4 & 5 \\
\hline 1. Entity Beliefs about Anxiety (IBSA) & 7.08 & 3.49 & $4-20$ & .75 & 1 & $.54^{* *}$ & -.13 & -.36 & .37 \\
\hline 2. Social Anxiety (LSAS-SR) & 50.50 & 19.97 & $0-144$ & .91 & & 1 & .10 & $-.70^{* *}$ & $.67^{*}$ \\
\hline 3. Social Costs (SCQ) & 187.08 & 40.66 & $0-320$ & .97 & & & 1 & $-.39^{*}$ & .32 \\
\hline 4. Perceived Social Self-Efficacy (PSSE) & 69.70 & 20.89 & $0-120$ & .90 & & & & 1 & $-.77^{* *}$ \\
\hline 5. Maladaptive Interpersonal Beliefs (MIB & ) 23.00 & 6.93 & $9-45$ & .85 & & & & & 1 \\
\hline
\end{tabular}

Note: IBSA = Implicit Beliefs about Social Anxiety Scale; LSAS-SR = Liebowitz Social Anxiety Scale-Self Report. ${ }^{*} p<.05,{ }^{* *} p<.01,{ }^{* * *} p<.001$ 
Table 3. Hierarchical Regression Predicting Post-Treatment Variance in Social Anxiety (LSASSR) accounting for Baseline Anxiety and Alternative Belief Measures ( $n=53)$.

\begin{tabular}{|c|c|c|c|c|c|c|}
\hline & B & SE B & $\beta$ & $\mathrm{R}^{2}$ & $\begin{array}{c}\mathrm{R}^{2} \\
\text { change }\end{array}$ & $F$ \\
\hline Step 1 & & & & $.47 * * *$ & & $14.48^{* * *}$ \\
\hline 1. Social Costs (SCQ) & .01 & .05 & .01 & & & \\
\hline 2. Perceived Social Self-Efficacy (PSSE) & -.14 & .15 & -.15 & & & \\
\hline 3. Maladaptive Interpersonal Beliefs (MIBS) & $1.5 *$ & .41 & $.57 *$ & & & \\
\hline Step 2 & & & & $.52^{* * *}$ & $.05 *$ & $13.22 * * *$ \\
\hline 1. Social Costs (SCQ) & .02 & .05 & .06 & & & \\
\hline 2. Perceived Social Self-Efficacy (PSSE) & -.06 & .15 & -.07 & & & \\
\hline 3. Maladaptive Interpersonal Beliefs (MIBS) & $1.19 * *$ & .41 & $.45^{* *}$ & & & \\
\hline 4. Entity Beliefs about Anxiety (IBSA) & $1.37 *$ & .59 & $.29 *$ & & & \\
\hline
\end{tabular}

Note: LSAS-SR = Liebowitz Social Anxiety Scale-Self Report; IBSA = Implicit Beliefs about Social Anxiety Scale. Adjusted $\mathrm{R}^{2}$ values and increments for $\mathrm{R}^{2}$ change are based upon $\mathrm{F}$ tests for that step.

$* p<.05, * * p<.01, * * * p<.001$ 
Figure 1. Implicit beliefs about anxiety for patients with social anxiety disorder (SAD) at baseline and post-treatment.

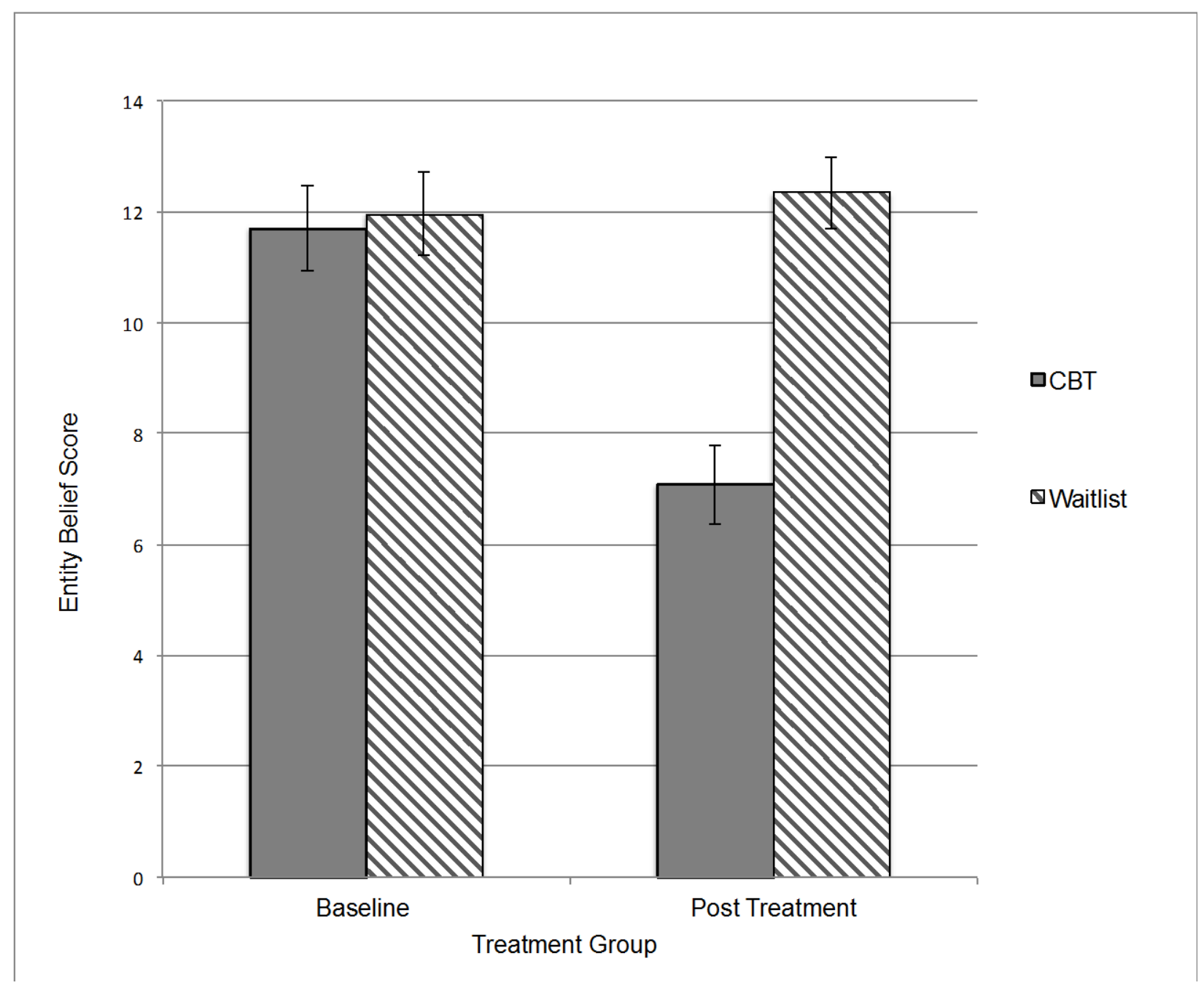

Note: At baseline patients in CBT and WL groups did not differ in their implicit beliefs about anxiety. Post-treatment entity beliefs about anxiety declined for patients receiving CBT $(n=24)$ but not for waitlist patients ( $n=29)$. Error bars represent the standard error of the mean. 
Figure 2. The indirect effect of patients' implicit beliefs about anxiety on post-CBT social anxiety, while controlling for baseline social anxiety symptoms.

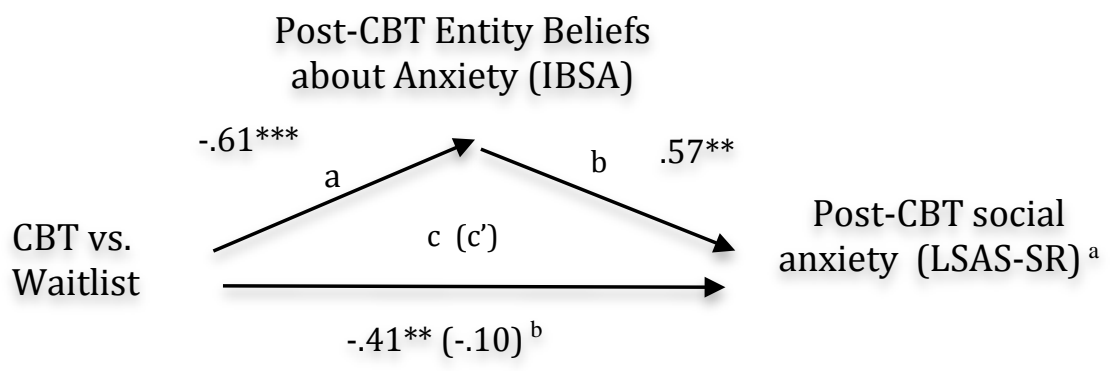

The regression coefficient for the effect of treatment decreases when controlling for implicit beliefs about anxiety. Values are standardized regression coefficients. ${ }^{a}$ LSAS-SR residuals represent post-CBT social anxiety (LSAS-SR) controlling for baseline social anxiety ${ }^{\mathrm{b}}$ When controlling for implicit beliefs about anxiety, the association between treatment and social anxiety is no longer significant . IBSA = Implicit Beliefs about Social Anxiety; LSAS-SR = Liebowitz Social Anxiety Scale - Self-report. 


\section{References}

American Psychiatric Association. (1994). Diagnostic and statistical manual of mental disorders (DSM-IV) (4th ed.). Washington, DC: American Psychiatric Publishing.

Arnkoff, D. B., Glass, C. R., \& Shapiro, D. A. (2002). Expectations and preferences. In J. C. Norcross (Ed.), Psychotherapy relationships that work (pp. 335-356). Oxford: University Press.

Bandura, A. (1997). Self-efficacy: The exercise of control. New York, NY: W.H. Freeman \& Company.

Baron, R. M., \& Kenny, D. A. (1986). The moderator-mediator variable distinction in social psychological research: conceptual, strategic, and statistical considerations. Journal of Personality and Social Psychology, 51(6), 1173-1182. doi: 10.1037/0022-3514.51

Blackwell, L. S., Trzesniewski, K. H., \& Dweck, C. S. (2007). Implicit theories of intelligence predict achievement across an adolescent transition: A longitudinal study and an intervention. Child Development, 78, 246-263. doi: 10.1111/j.1467-8624.2007.00995.x

Boden, M. T., John, O. P., Goldin, P. R., Werner, K., Heimberg, R. G., \& Gross, J. J. (2012). The role of maladaptive beliefs in cognitive-behavioral therapy: Evidence from social anxiety disorder. Behaviour Research and Therapy, 50, 287-291. doi: 10.1016/j.brat.2012.02.007

Brown, T. A., DiNardo, P., \& Barlow, D. H. (1994). Anxiety Disorders Interview Schedule Lifetime Version (ADIS-IV-L). New York, NY: Oxford University Press.

Brozovich, F. A., \& Heimberg, R. G. (2011). A treatment refractory case of social anxiety disorder: Lessons learned from a failed course of cognitive-behavioral therapy. Cognitive and Behavioral Practice, 18, 316-325. doi: 10.1016/j.cbpra.2010.07.003

Bruch, M. A., Fallon, M., \& Heimberg, R. G. (2003). Social phobia and difficulties in occupational adjustment. Journal of Counseling Psychology, 50, 109-117. doi: 10.1037/0022-0167.50.1.109 
Buckner, J. D., \& Schmidt, N. B. (2009). A randomized pilot study of motivation enhancement therapy to increase utilization of cognitive-behavioral therapy for social anxiety. Behaviour Research and Therapy, 47, 710-715. doi: 10.1016/j.brat.2009.04.009

Chambless, D. L., Tran, G. Q., \& Glass, C. R. (1997). Predictors of response to cognitivebehavioral group therapy for social phobia. Journal of Anxiety Disorders, 11, 221-240. doi: 10.1016/S0887-6185(97)00008-X

Clark, D. M. (2001). A cognitive perspective on social phobia. In W. R. Crozier \& L. E. Alden (Eds.), International handbook of social anxiety: Concepts, research and interventions relating to the self and shyness. New York: John Wiley \& Sons.

Clark, D. M., Ehlers, A., Hackmann, A., McManus, F., Fennell, M., Grey, N., . . W Wild, J. (2006). Cognitive therapy versus exposure and applied relaxation in social phobia: A randomized controlled trial. Journal of Consulting and Clinical Psychology, 74, 568-578. doi: 10.1037/0022-006X.74.3.568

Clark, D. M., Ehlers, A., McManus, F., Hackmann, A., Fennell, M., Campbell, H., .. . Louis, B. (2003). Cognitive therapy versus fluoxetine in generalized social phobia: a randomized placebo-controlled trial. Journal of Consulting and Clinical Psychology, 71, 1058-1067. doi: 10.1037/0022-006X.71.6.1058

Clark, D. M., \& Wells, A. (1995). A cognitive model of social phobia. In R. G. Heimberg, M. R. Liebowitz, D. A. Hope, \& F. R. Schneier (Eds.), Social phobia: Diagnosis, assessment and treatment (pp. 69-93). New York: The Guilford Press.

Cohen, J. (1988). Statistical power analysis for the behavioral sciences. Hillsdale, New Jersey: Lawrence Erlbaum Associates Publishers.

Cohen, J., Cohen, P., West, S. G., \& Aiken, L. S. (2003). Applied multiple regression/correlation analysis for the behavioral sciences (3rd ed.). Mahwah, NJ: Lawrence Erlbaum Associates. 
De Castella, K., Goldin, P., Jazaieri, H., Ziv, M., Dweck, C. S., \& Gross, J. J. (2013). Beliefs about emotion: Links to emotion regulation, well-being, and psychological distress. Basic and Applied Social Psychology, 35, 497-505. doi: 10.1080/01973533.2013.840632

De Castella, K., Goldin, P., Jazaieri, H., Ziv, M., Heimberg, R. G., \& Gross, J. J. (2014). Emotion beliefs in social anxiety disorder: Associations with stress, anxiety, and wellbeing. Australian Journal of Psychology, 66, 130-148. doi: 10.1111/ajpy.12053

Dweck, C. S. (1999). Self-theories: Their role in motivation, personality, and development. Philadelphia: Psychology Press.

Foa, E. B., Franklin, M. E., Perry, K. J., \& Herbert, J. D. (1996). Cognitive biases in generalized social phobia. Journal of Abnormal Psychology, 105, 433-439. doi: 10.1037/0021843X.105.3.433

Fresco, D. M., Coles, M. E., Heimberg, R. G., Liebowitz, M. R., Hami, S., Stein, M. B., \& Goetz, D. (2001). The Liebowitz Social Anxiety Scale: A comparison of the psychometric properties of self-report and clinician-administered formants. Psychological Medicine, 31, 1025-1035. doi: 10.1017\S003329170105405

Gaudiano, B. A., \& Herbert, J. D. (2003). Preliminary psychometric evaluation of a new selfefficacy scale and its relationship to treatment outcome in social anxiety disorder. Cognitive Therapy and Research, 27, 537-555. doi: 10.1023/A:1026355004548

Goldin, P. R., Ziv, M., Jazaieri, H., Werner, K., Kraemer, H., Heimberg, R. G., \& Gross, J. J. (2012). Cognitive reappraisal self-efficacy mediates the effects of individual cognitivebehavioral therapy for social anxiety disorder. Journal of Consulting and Clinical Psychology, 80, 1034-1040. doi: 10.1037/a0028555

Good, C., Aronson, J., \& Inzlicht, M. (2003). Improving adolescents' standardized test performance: An intervention to reduce the effects of stereotype threat. Journal of Applied Developmental Psychology, 24, 645-662. doi: 10.1016/j.appdev.2003.09.002. 
Greenwald, A. G., McGhee, D. E., \& Schwartz, J. K. L. (1998). Measuring individual differences in implicit cognition: The Implicit Association Test. Journal of Personality and Social Psychology, 74, 1464-1480. doi: 10.1177/0146167205275613

Hayes, A. F. (2009). Beyond Baron and Kenny: Statistical mediation analysis in the new millennium. Communication Monographs, 76(4), 408-420. doi: 10.1080/03637750903310360.

Heimberg, R. G., Brozovich, F. A., \& Rapee, R. M. (2010). A cognitive-behavioral model of social anxiety disorder: Update and extension (2nd edition, pp.395-422). Social anxiety: Clinical, developmental, and social perspectives. New York, NY: Academic Press.

Heimberg, R. G., Brozovich, F. A., \& Rapee, R. M. (2014). A cognitive-behavioral model of social anxiety disorder. In S. G. Hofmann \& P. M. DiBartolo (Eds.), Social Anxiety: Clinical, developmental, and social perspectives (3rd edition ed., pp. 705-728). Waltham, MA: Academic Press.

Heimberg, R. G., Salzman, D. G., Holt, C. S., \& Blendell, K. A. (1993). Cognitive-behavioral group treatment for social phobia: Effectiveness at five-year follow-up. Cognitive Therapy and Research, 17, 325-339. doi: 10.1007/BF01177658

Hertel, P. T., \& Mathews, A. (2011). Cognitive bias modification. Perspectives on Psychological Science, 6, 521 - 536. doi: 10.1177/1745691611421205

Hofmann, S. G. (2000). Treatment of social phobia: Potential mediators and moderators. Clinical Psychology, 7, 3-16. doi: 10.1093/clipsy.7.1.3.

Hofmann, S. G. (2004). Cognitive mediation of treatment change in social phobia. Journal of Consulting and Clinical Psychology, 72, 393-399. doi: 10.1037/0022-006X.72.3.393

Hofmann, S. G. (2005). Perception of control over anxiety mediates the relation between catastrophic thinking and social anxiety in social phobia. Behaviour Research and Therapy, 43, 885-895. doi: 10.1016/j.brat.2004.07.002 
Hofmann, S. G. (2007). Cognitive factors that maintain social anxiety disorder: A comprehensive model and its treatment implications. Cognitive Behaviour Therapy, 36, 193-209. doi: 10.1080/16506070701421313.

Hofmann, S. G., \& Barlow, D. H. (2002). Social phobia (social anxiety disorder). In D. H. Barlow (Ed.), Anxiety and its disorders: The nature and treatment of anxiety and panic (2nd ed., pp. 454-476). New York: Guilford Press.

Hofmann, S. G., Ehlers, A., \& Roth, W. T. (1995). Conditioning theory: A model for the etiology of public speaking anxiety? Behaviour Research and Therapy, 33, 567-571. doi: 10.1016/0005-7967(94)00072-R

Hofmann, S. G., Moscovitch, D. A., Kim, H. J., \& Taylor, A. N. (2004). Changes in selfperception during treatment of social phobia. Journal of Consulting and Clinical Psychology, 72, 588-596. doi: 10.1037/0022-006x.72.4.588

Hope, D. A., Heimberg, R. G., Juster, H., \& Turk, C. L. (2000). Managing social anxiety: A cognitive-behaivoral therapy approach (Client Workbook). New York: Oxford University Press.

Hope, D. A., Heimberg, R. G., \& Turk, C. L. (2006). Therapist guide for Managing Social Anxiety: A cognitive-behavioral therapy approach. New York: Oxford University Press.

Hope, D. A., VanDyke, M., Heimberg, R. G., Turk, C. L., \& Fresco, D. M. (2001). Cognitivebehavioral therapy for social anxiety disorder: Therapist adherence scale.: Available from Richard G. Heimberg, Adult Anxiety Clinic of Temple University, 1701 North 13th Street, Philadelphia, PA 19122-6085.

Kashdan, T. B., \& Herbert, J. D. (2001). Social anxiety disorder in childhood and adolescence: Current status and future directions. Clinical Child and Family Psychology Review, 4, 3761. doi: 10.1023/A:1009576610507 
Kendall, P. C., \& Treadwell, K. R. H. (2007). The role of self-statements as a mediator in treatment for youth with anxiety disorders. Journal of Consulting and Clinical Psychology, 75, 380-389. doi: 10.1037/0022-006x.75.3.380

Kessler, R., Berglund, P., Demler, O., Jin, R., Merikangas, K. R., \& Walters, E. E. (2005). Lifetime prevalence and age-of-onset distributions of DSM-IV disorders in the national comorbidity survey replication. Archives of General Psychiatry, 62, 593-602. doi: 10.1001/archpsyc.62.6.593.

Kessler, R., Chiu, W. T., Demler, O., Merikangas, K. R., \& Walters, E. E. (2005). Prevalence, severity, and comorbidity of 12-month DSM-IV disorders in the national comorbidity survey replication. Archives of General Psychiatry, 62, 617-627. doi: 10.1001/archpsyc.62.6.617.

Kessler, R., Chiu, W. T., Jin, R., Ruscio, A. M., Shear, K., \& Walters, E. E. (2006). The epidemiology of panic attacks, panic disorder, and agoraphobia in the National Comorbidity Survey Replication. Archives of General Psychiatry, 63, 415-424. doi: 10.1001/archpsyc.63.4.415

Leary, M. R., \& Atherton, S. C. (1986). Self-efficacy, social anxiety, and inhibition in interpersonal encounters. Journal of Social and Clinical Psychology, 4, 256-267. doi: 10.1521/jscp.1986.4.3.256

Ledley, D. R., Erwin, B. A., Morrison, A. S., \& Heimberg, R. G. (2013). Social anxiety disorder. In W. E. Craighead, D. J. Miklowitz, \& L. W. Craighead (Eds.), Psychopathology: History, theory, and empirical foundations, 2nd edition (pp. 147-192). New York: John Wiley \& Sons.

Ledley, D. R., Heimberg, R. G., Hope, D. A., Hayes, S. A., Zaider, T. I., Dyke, M. V., . . Fresco, D. M. (2009). Efficacy of a manualized and workbook-driven individual treatment for social anxiety disorder. Behavior Therapy, 40, 414-424. doi: 10.1016/j.beth.2008.12.001 
Leichsenring, F., Salzer, S., Beutel, M. E., Herpertz, S., Hiller, W., Hoyer, J., . . L Leibing, E. (2013). Psychodynamic therapy and cognitive-behavioral therapy in social anxiety disorder: A multicenter randomized controlled trial. American Journal of Psychiatry, 170, 759-767. doi: 10.1176/appi.ajp.2013.12081125

Mansell, W., \& Clark, D. M. (1999). How do I appear to others? Social anxiety and processing of the observable self. Behaviour Research and Therapy, 37, 419-434. doi: 10.1016/S0005-7967(98)00148-X

Miller, W. R., \& Rollnick, S. (2002). Motivational interviewing: Preparing people for change (2nd edition). New York, NY: Guilford Press.

Miller, W. R., Zweben, A., DiClemente, C. C., \& Rychtarik, R. G. (1992). Motivational enhancement therapy manual: A clinical research guide for therapists treating individuals with alcohol abuse and dependence. Rockville, MD: National Institute on Alcohol Abuse and Alcoholism (NIAAA).

Montesi, J. L., Conner, B. T., Gordon, E. A., Fauber, R. L., Kim, K. H., \& Heimberg, R. G. (2012). On the relationship among social anxiety, intimacy, sexual communication, and sexual satisfaction in young couples. Archives of Sexual Behavior, 42, 89-91. doi: 10.1007/s10508-012-9929-3

Mortberg, E., Clark, D. M., \& Bejerot, S. (2011). Intensive group cognitive therapy and individual cognitive therapy for social phobia: Sustained improvement at 5-year followup. Journal of Anxiety Disorders, 25, 994-1000. doi: 10.1016/j.janxdis.2011.06.007

Mortberg, E., Clark, D. M., Sundin, O., \& Aberg Wistedt, A. (2007). Intensive group cognitive treatment and individual cognitive therapy vs. treatment as usual in social phobia: a randomized controlled trial. Acta Psychiatrica Scandinavica, 115, 142-154. doi: 10.1111/j.1600-0447.2006.00839.x 
Preacher, K. J., \& Hayes, A. F. (2008). Asymptotic and resampling strategies for assessing and comparing indirect effects in multiple mediator models. Behavior Research Methods, 40(3), 879-891. doi: 10.3758/BRM.40.3.879

Preacher, K. J., \& Kelley, K. (2011). Effect size measures for mediation models: quantitative strategies for communicating indirect effects. Psychological Methods, 16(2), 93-115. doi: 10.1037/a0022658

Price, M., \& Anderson, P. L. (2011). Outcome expectancy as a predictor of treatment response in cognitive behavioral therapy for public speaking fears within social anxiety disorder. Psychotherapy, 49, 1-7. doi: 10.1037/a0024734

Rapee, R. M., Gaston, J. E., \& Abbott, M. J. (2009). Testing the efficacy of theoretically derived improvements in the treatment of social phobia. Journal of Consulting and Clinical Psychology, 77, 317-327. doi: 10.1037/a0014800

Reich, J., Goldenberg, I., Vasile, R., Goisman, R., \& Keller, M. (1994). A prospective followalong study of the course of social phobia. Psychiatry Research, 54, 249-258. doi: 10.1016/0165-1781(94)90019-1

Rodebaugh, T. L. (2009). Social phobia and perceived friendship quality. Journal of Anxiety Disorders, 23, 872-878. doi: 10.1016/j.janxdis.2009.05.001

Rucker, D. D., Preacher, K. J., Tormala, Z. L., \& Petty, R. E. (2011). Mediation analysis in social psychology: Current practices and new recommendations. Social and Personality Psychology Compass, 5(6), 359-371. doi: 10.1111/j.1751-9004.2011.00355.x

Schneier, F. R., Heckelman, L. R., Garfinkel, R., Campeas, R., Fallon, B. A., Gitow, A., .. . Liebowitz, M. R. (1994). Functional impairment in social phobia. Journal of Clinical Psychiatry, 55, 322-331. doi: 1995-04074-001

Smith, H. M., \& Betz, N. E. (2000). Development and validation of a scale of perceived social self-efficacy. Journal of Career Assessment, 8, 283-301. doi: 
Smits, J. A. J., Julian, K., Rosenfield, D., \& Powers, M. B. (2012). Threat reappraisal as a mediator of symptom change in cognitive-behavioral treatment of anxiety disorders: A systematic review. Journal of Consulting and Clinical Psychology, 80, 624-635. doi: 10.1037/a0028957

Sobel, M. E. (1982). Asymptotic confidence intervals for indirect effects in structural equation models. Sociological Methodology, 13, 290-312. doi: 10.2307/270723

Stangier, U., Schramm, E., Heidenreich, T., Berger, M., \& Clark, D. M. (2011). Cognitive therapy vs interpersonal psychotherapy in social anxiety disorder: A randomized controlled trial. Archives of General Psychiatry, 68, 692-700. doi: 10.1001/archgenpsychiatry.2011.67

Tabachnick, B. G., \& Fidell, L. S. (2007). Using multivariate statistics. New Jersey: Pearson Education Limited.

Tamir, M., John, O. P., Srivastava, S., \& Gross, J. J. (2007). Implicit theories of emotion: Affective and social outcomes across a major life transition. Journal of Personality and Social Psychology, 92, 731-744. doi: 10.1037/0022-3514.92.4.731

Tamir, M., \& Mauss, I. B. (2011). Social cognitive factors in emotion regulation: Implications for well-being. In I. Nyklicek, A. Vingerhoets, M. Zeelenberg, \& J. Donellet (Eds.), Emotion regulation and well-being (pp. 31-47). New York: Springer.

Wagner, R., Silove, D., Marnane, C., \& Rouen, D. (2006). Delays in referral of patients with social phobia, panic disorder and generalized anxiety disorder attending a specialist anxiety clinic. Journal of Anxiety Disorders, 20, 363-371. doi: 10.1016/j.janxdis.2005.02.003

Werner, K. H., Goldin, P. R., Ball, T. M., Heimberg, R. G., \& Gross, J. J. (2011). Assessing emotion regulation in social anxiety disorder: The Emotion Regulation Interview. Journal of Psychopathology and Behavioral Assessment, 33, 346-354. doi: 
Werner, K. H., \& Gross, J. J. (2009). Emotion regulation and psychopathology: A conceptual framework. In A. M. Kring \& D. M. Sloan (Eds.), Emotion regulation and psychopathology: A transdiagnostic approach to etiology and treatment (pp. 13). New York: Guilford Press.

Westra, H. A., Arkowitz, H., \& Dozois, D. J. (2009). Adding a motivational interviewing pretreatment to cognitive behavioral therapy for generalized anxiety disorder: A preliminary randomized controlled trial. Journal of Anxiety Disorders, 23, 1106-1117. doi: 10.1016/j.janxdis.2009.07.014

Wong, J., Gordon, E. A., \& Heimberg, R. G. (2012). Social anxiety disorder. In P. Sturmey \& M. Hersen (Eds.), Handbook of evidence-based practice in clinical psychology: Volume II, Adult disorders (pp. 621-649). New York: John Wiley \& Sons, Inc. 